\title{
SERUM AND URINE COPPER - CONTAMINATION AND STABILITY
}

\author{
I. Ivanova', B. Atanasova², M. Petrova², S. Dragneva ${ }^{3}$, L. Vladimirova ${ }^{3}$, Z. Krastev³, \\ A. Kostadinova ${ }^{4}$, A. Ivanova ${ }^{1}$ and K. Tzatchev ${ }^{2}$ \\ ${ }^{1}$ Clinical Laboratory Deparment, University Hospital Sv. Ivan Rilski, Medical University - Sofia \\ ${ }^{2}$ Department of Clinical Laboratory and Immunology, University Hospital Alexandrovska, \\ Medical University - Sofia \\ ${ }^{3}$ Clinic of Gastroenterology, University Hospital Sv. Ivan Rilski, Medical University - Sofia \\ ${ }^{4}$ Clinic of Nephrology, University Hospital Sv. Ivan Rilski, Medical University - Sofia
}

Summary. Pre-analytical factors of variation need to be carefully considered and investigated in efforts to harmonize all aspects of the total testing process. This study aimed to evaluate contamination and stability in copper $(\mathrm{Cu})$ analysis of serum and urine by flame atomic absorption spectroscopy (FAAS) and to compare the stability of urine $\mathrm{Cu}$ in controls and in D-penicillamine (D-PA) administration. Cu was measured by AAnalyst 400, Perkin Elmer, USA. Blood was collected in BD Vacutainer ${ }^{\circledR}$ SSTTM II Advance tubes and BD Vacutainer ${ }^{\circledR}$ Trace Element tubes. Sterile polyethylene and polypropylene vessels for collection, transportation, storage and preliminary preparation of samples were used in urinalysis. Stability in serum and $24 \mathrm{~h}$ urine was evaluated in two temperature regimens: $15-25^{\circ} \mathrm{C}$ and $2-8^{\circ} \mathrm{C}$, for particular time of storage. No significant differences $(p=0.20)$ in $\mathrm{Cu}$ concentration was found between the two types of tested tubes with patient's sera. The stability of the samples (serum and urine) was better at refrigeration temperature. In urine the stability was better in D-PA administration.Standardization of $\mathrm{Cu}$ analysis could be achieved by assessing the aspects of pre-analytical factors of variations.

Key words: $\mathrm{Cu}$, atomic absorption, pre-analytical phase, contamination, stability, $D$ penicillamine 


\section{INTRODUCTION}

aboratory error is defined as "any defect from ordering tests to reporting results and appropriately interpreting and reacting on these" [2]. In laboratory medicine, the vast majority of errors (60-75\%) occur in the preanalytical phase of the testing process [11, 12], especially those related to collection, handling, transportation, preparation and storage of diagnostic specimens [9]. Pre-analytical factors of variation need to be carefully investigated as components of quality assurance system in efforts to harmonize all the aspects of the total testing process. This issue is also a key point in trace element determinations. Contamination errors are common in this case. They can occur during all pre-analytical steps. It is necessary to examine all devices and tubes for copper $(\mathrm{Cu})$ content to avoid eventual non-predictable contamination, even stated that they are suitable [5].

The aim of this study was to evaluate the following pre-analytical factors for $\mathrm{Cu}$ determination in serum and urine using FAAS: I) the influence of the serum collection tubes type; II) urine contamination from all tubes in pre-analytical phase - for collection, transportation and storage, and dilution of urine samples; III) temperature and time of sample (serum and urine) storage since collection to analysis; IV) D-PA intake on Cu stability of urine specimen.

\section{MATERIAL AND METHODS}

The study was conducted in 2013-2014 at Central Clinical Laboratory of University Hospital "St. Ivan Rilski", Medical University - Sofia, Bulgaria. All included individuals signed informed consent form in accordance with Helsinki Declaration Guidelines for Experimentations Involving Humans. Approval of Research Ethical Committee of Medical University - Sofia, Bulgaria, was obtained too. Blood was collected from healthy individuals $(n=10)$ and was drawn between 7:30-9:30 am by standard collection procedure followed by $12 \mathrm{~h}$ fasting pause overnight. Urine samples were collected as diuresis for $24 \mathrm{~h}$ from 28 controls (from Clinic of Nephrology) and 14 patients on D-PA administration (from Clinic of Gastroenterology).

Evaluation of the influence of the serum collection tubes type

The following sterile blood collection tubes were examined:

1) BD Vacutainer ${ }^{\circledR}$ BD SST TM II Advance (BD Serum Separator tubes); serum separate acrylic based gel and a spray dried clot activator coating; plastic material; $5 \mathrm{ml}$; Cat. № 367955).

2) BD Vacutainer ${ }^{\circledR}$ Trace Element Tubes (BD Trace Element tubes); clot activator; silicone coated interior; plastic material; 6 ml; Cat. № 368380 .

Blood of one and the same healthy individuals $(n=10)$ was drawn into both types of serum tubes and Cu was analyzed up to $2 \mathrm{~h}$ since blood collection and after centrifugation at standartised conditions: $\leq 1200 \mathrm{~g}$ for $10 \mathrm{~min}$ at $25^{\circ} \mathrm{C}$ (Centrifuge UNIVERSAL 320, 1401/1406, Hettich zentrifugen, Germany). 
Evaluation urine contamination from all tubes in pre-analytical phase for collection, transportation and storage, and dilution of urine samples

The following tubes were examined:

1) Containers for urine collection $(n=10)$ - sterile cylindrical containers graduated up to $2 \mathrm{~L}$; with handle; polyethylene material; wide neck with a cap; singlehanded use (Cat. № 40800.1; Deltalab, Spain). They were filled with de-ionized water and $\mathrm{Cu}$ concentration in water extracts was analyzed at different time intervals after vessel filling: $\mathrm{T}_{0}$ - immediately after filling, then 6,18 and $24 \mathrm{~h}$ after filling.

2) Cups for delivery and storage of urine samples $(n=15)-50 \mathrm{~mL}$ vessels with polyethylene caps; ultra clear polypropylene material; single-handed use (Cat. № 409802; Deltalab, Spain). They were filled with: 1. Distilled water and 2. Mild acid extraction solution of $1 \%$ nitric acid (prepared from stock $65 \% \mathrm{HNO}_{3}$, pro analysis, Merck $\mathrm{KGaA}$, Darmstadt, Germany). The initial concentration $\left(\mathrm{T}_{0}\right)$ was measured right after filling. Then, the cups were kept at room temperature for 2, 24 and $48 \mathrm{~h}$ after filling. For every time interval, $\mathrm{Cu}$ concentrations both in water and acid extracts were measured.

3) Tubes for preliminary sample preparation (dilution) before $\mathrm{Cu}$ measurement, $(n=15)$ - conical centrifuge tubes; $15 \mathrm{~mL}$; sterile; polypropylene material (Cat. № 352003; BD FalconTM). They were filled with de-ionized water and kept at room temperature for $2 \mathrm{~h}$. Cu concentration was measured in water extracts right after filling (initial concentration $\mathrm{T}_{0}$ ) and after $2 \mathrm{~h}$.

The contamination testing scheme comprised the following steps:

1. Filling with distilled water (or mild acid solution or with $1 \% \mathrm{HNO}_{3}$ ) to the pointed final volume and inverted 50-60 times in order to mix and dissolve chemical additives (coating) adequately. Right after filling, the initial time concentration was measured $\left(\mathrm{T}_{0}\right)$. Then the vessels were kept for particular time intervals after filling at room temperature and $\mathrm{Cu}$ concentration was determined in aqueous extracts.

2. Each vessel was checked by the instrument 6 times, a mean value was calculated automatically.

3. Distilled water was checked for $\mathrm{Cu}$ concentration. The results were considered to be "blank-values" and were taken into account when calculating every single tube.

\section{Temperature and time of sample (serum and urine) storage since collec- tion to analysis \\ Cu stability in serum specimens}

Totally 11 sera, chosen from routine clinical chemistry orders, were tested. Blood was drawn into blood tubes for serum collection BD Serum Separated tubes. Samples were centrifuged at $\leq 1200 \mathrm{~g}$ for $10 \mathrm{~min}$, at room temperature (Centrifuge UNIVERSAL 320, 1401/1406, Hettich zentrifugen, Germany) and were analyzed up to $2 \mathrm{~h}$ after blood collection (initial $\mathrm{Cu}$ serum concentration $-\mathrm{ST}_{0}$ ). Serum aliquots were transferred to small plastic Eppendorf tubes of $1.5 \mathrm{~mL}$ for storage. To avoid possible evaporation, the tubes with serum were kept closed during the whole storage. The following conditions were tested: 
- Temperature regimen: room temperature $-15-25^{\circ} \mathrm{C}$ and temperature of refrigeration $-2-8^{\circ} \mathrm{C}$

- Time for storage: one week storage $\left(\mathrm{ST}_{1}\right)$ and two weeks storage $\left(\mathrm{ST}_{2}\right)$.

\section{Cu stability in urine specimens}

The study examined Cu stability in $24 \mathrm{~h}$ urine of 28 control individuals with no evidence for disordered $\mathrm{Cu}$ balance and on the other hand the stability of the measured in $24 \mathrm{~h}$ urine of 14 patients on D-PA administration. The intake of D-PA was $1000 \mathrm{mg}$ twice daily. The patients were instructed to void urine the next day after medicine intake directly into the collective container and not to leave the container open longer than necessary according to recommendations by IUPAC [15]. The collection containers were kept refrigerated during the $24 \mathrm{~h}$ collection period [10]. No preservatives were added into the urine samples during sample collection and storage. At the end of the collection period, after mixing of vessel content by inversion, urine aliquot was put into $50 \mathrm{ml}$ polypropylene small sterile crew-capped cup for delivery. Urine samples with certain measured volume were delivered to the Central Laboratory and urine $\mathrm{Cu}$ was determined. The small plastic cups (closed until analysis) were used also for storage of urine samples. Stability evaluation was done against initial $\mathrm{Cu}$ urine concentration measured within $2 \mathrm{~h}$ after delivery of $24 \mathrm{~h}$ urine samples to the laboratory (initial urine concentration - UT ${ }_{0}$ ). The following storage temperatures and time intervals were assessed:

- Temperature regimen: room temperature $-15-25^{\circ} \mathrm{C}$ and temperature of refrigeration $-2-8^{\circ} \mathrm{C}$

- Time for storage: 2 days ( $\left.\mathrm{UT}_{1}\right), 3$ days ( $\left.\mathrm{UT}_{2}\right)$ and 14 days $\left(\mathrm{UT}_{3}\right)$.

\section{Quantitative $\mathrm{Cu}$ determination}

All Cu measurements in serum, urine and aqueous extracts were done by flame atomic absorption spectrophotometry (FAAS; Perkin Elmer AAnalyst 400, USA). The instrumental parameters of the spectrophotometer are pointed on Table 1. Determination of $\mathrm{Cu}$ concentration was done after 3 point calibration by standard calibration solutions with known concentration: $7.87 ; 15.74 ; 23.61 \mu \mathrm{mol} / \mathrm{L}$, prepared by proper dilution with de-ionized water of Cu stock standard (1000 mg/L, in $2 \% \mathrm{HNO}_{3}$, Lot № 19-09 CUX1, Perkin Elmer Pure, USA).

Table 1. Instrumental parameters of flame atomic absorption spectrophotometer Perkin Elmer AAnalyst 400

\begin{tabular}{|l|l|}
\hline Parameters & \\
\hline Wavelength (nm) & 324.8 \\
\hline Spectral Bandwidth (Slit) $(\mathrm{nm})$ & 0.7 \\
\hline Light Source & Hollow Cathode Lamp (HCL) \\
\hline Light Current (mA) & 15 \\
\hline Atomizer & Flame air-acetylene \\
\hline Sample introduction into atomizer & $\begin{array}{l}\text { Pulverization following: } \\
\text { Preliminary dilution of serum samples 1:4 and of urine samples 1:3 (by distilled water) }\end{array}$ \\
\hline
\end{tabular}




\section{Quality accuracy}

Internal Quality Control (IQC) scheme was applied (certificate reference materials Seronorm ${ }^{\mathrm{TM}}$ Trace Elements Serum, Sero, Norway; Level 1 Lot № 0903106 and Level 2 Lot № 0903107 for Cu serum and Seronorm ${ }^{\text {TM }}$ Trace Elements Urine, Sero, Norway; Level 1 Lot № 1011644 and Level 2 Lot № 1011645 for Cu urine). Interassay analytical imprecision was presented on Table 2.

Table 2. Inter-assay imprecision (CV\%) for serum and urine $\mathrm{Cu}$. $\mathrm{CV} \%$ was obtained as a mean value of quality control data accumulated over a 3 month period for urine $\mathrm{Cu}$

\begin{tabular}{|l|l|l|}
\hline Analyte & Target value $(\boldsymbol{\mu m o l} / \mathbf{L})$ & Inter-assay Imprecision $\mathbf{C V} \%$ \\
\hline Serum Cu & 26.6 & 1.1 \\
\hline Urine Cu Level 2 & 0.35 & 6.0 \\
\hline Urine Cu Level 1 & 0.49 & 4.0 \\
\hline
\end{tabular}

\section{Statistical analysis}

The SPSS program (version 19.0) for Windows (SPSS, Chicago, IL, USA) was used for the statistical analysis. Our statistical plan included the following approaches:

1) The Kolmogorov-Smirnov test was used to assess the normality of distribution of investigated parameters. Results were expressed as Means \pm Standard deviation (SD). Differences were tested by t-tests. The values $p<0.05$ were considered statistically significant.

2) In serum Cu stability study the mean of all results of the tested specimens at the first time point represented the initial concentration $\left(\mathrm{ST}_{0}\right)$. The mean of all $\mathrm{Cu}$ results for the tested storage temperatures and delays before the same measurement represented the value STx. Mean percentage difference $((\mathrm{Tx}-\mathrm{T} 0) / \mathrm{T} 0) \times 100$ was calculated and compared to desirable specification for Allowable Total Error ATE $\%=7.47$ for serum $\mathrm{Cu}$, based on within-subject and between-subject biological variation (15). If the result for the mean percentage difference exceeded ATE, then the difference was judged to be significant and did not meet stability criteria.

3) In urine Cu stability study the mean of all results of the tested specimens at the first time point represented the initial concentration UTO. The mean of all $\mathrm{Cu}$ results for the tested storage temperatures and delays before the measurement represented the value Tx. Mean percentage difference (Tx-T0)/T0) x 100 was calculated and compared to Acceptable Change Limit (ACL), according to ISO 5725-6 [10]. $A C L=2.77 \times C V$ where $C V$ (coefficient of variation) is an analytical imprecision. Mean percentage difference greater than ACL represented a probable significant difference in analyte concentration. CVa was obtained as a mean value for inter-assay analytical imprecision of in house routine quality control data accumulated over a 3 month period for urine $\mathrm{Cu}$. 


\section{RESULTS}

In the experiment with patient's sera $\mathrm{Cu}$ for both groups of tested tubes were almost equal: $17.56 \pm 6.01 \mu \mathrm{mol} / \mathrm{L}$ in BD Serum Separator tubes and $17.76 \pm 6.00$ $\mu \mathrm{mol} / \mathrm{L}$ in BD Trace Element tubes with no statistical difference $p=0.20$ (Fig. 1).

The Mean \pm SD Cu in water extracts from different type of vessels and periods, in urine Cu measurement, were below evaluated detection limit of the method $(0.007 \mu \mathrm{mol} / \mathrm{L})$.

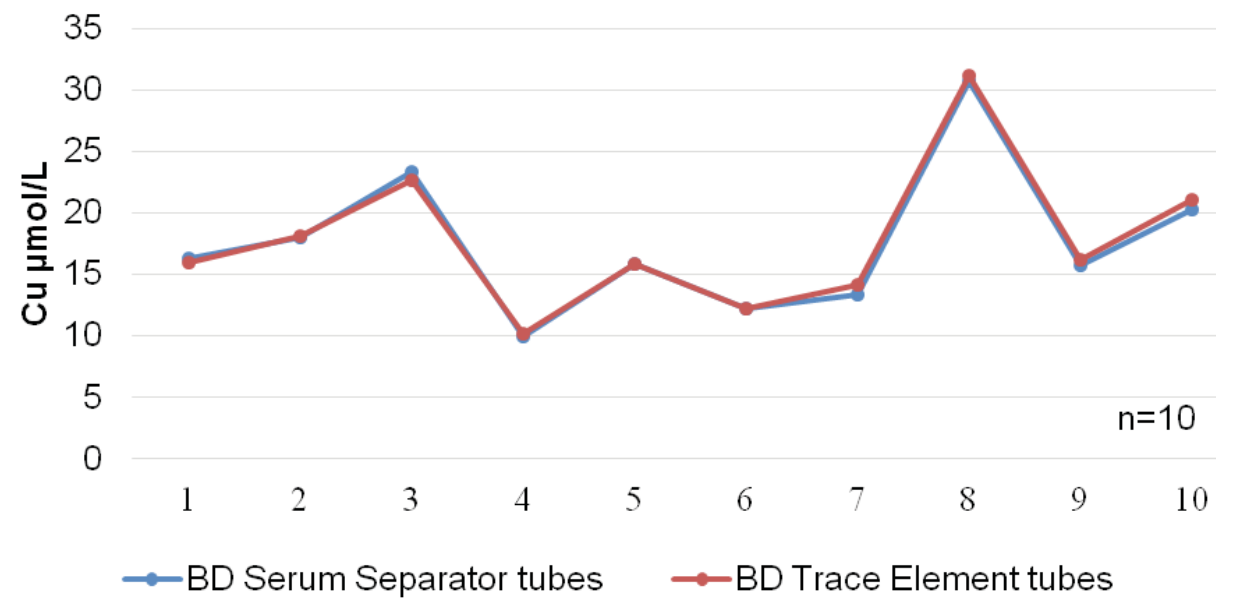

Fig. 1. $\mathrm{Cu}$ in serum from BD Serum Separation tubes and BD Trace Element tubes $(p=0.20)$

\section{Cu stability in serum specimens}

The data for Cu stability in serum are presented on Table 3 and Figure 2. We found significant decreasing in serum $\mathrm{Cu}$ concentration at room temperature for both time intervals in comparison to $\mathrm{ST}_{0}$ and no statistical difference between $\mathrm{ST}_{1}$ and $\mathrm{ST}_{2}(\mathrm{p}=0.617)$. Refrigeration for one week led to statistical increasing in serum $\mathrm{Cu}$ in comparison to the initial concentration $(p=0.025)$ and no statistical difference in serum $\mathrm{Cu}$ for 2 weeks refrigeration $(p=0.52)$. According to the ATE criterion all calculated mean percentage differences were under $7.47 \%$.

Table 3. Stability of $\mathrm{Cu}$ in serum

\begin{tabular}{|c|c|c|c|c|c|}
\hline \multirow{3}{*}{$\mathrm{ST}_{0} \mu \mathrm{mol} / \mathrm{L}$} & \multirow{3}{*}{ ATE $\%$} & \multicolumn{4}{|c|}{ Mean differences \% } \\
\hline & & \multicolumn{2}{|c|}{$\mathrm{ST}_{1}$} & \multicolumn{2}{|c|}{$\mathrm{ST}_{2}$} \\
\hline & & $25^{\circ} \mathrm{C}$ & $4^{\circ} \mathrm{C}$ & $25^{\circ} \mathrm{C}$ & $4^{\circ} \mathrm{C}$ \\
\hline 15.5 & 7.47 & -6.1 & 5.3 & -5.2 & -0.9 \\
\hline
\end{tabular}

$\mathrm{ST}_{0}$ - initial concentration; time for storage before analysis ( $\mathrm{ST}_{1}-1$ week; $\mathrm{ST}_{2}-2$ weeks); ATE - Allowable Total Error 


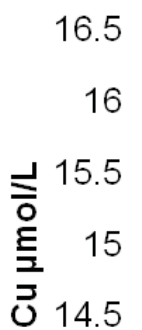

16.3

14.5

14

13.5

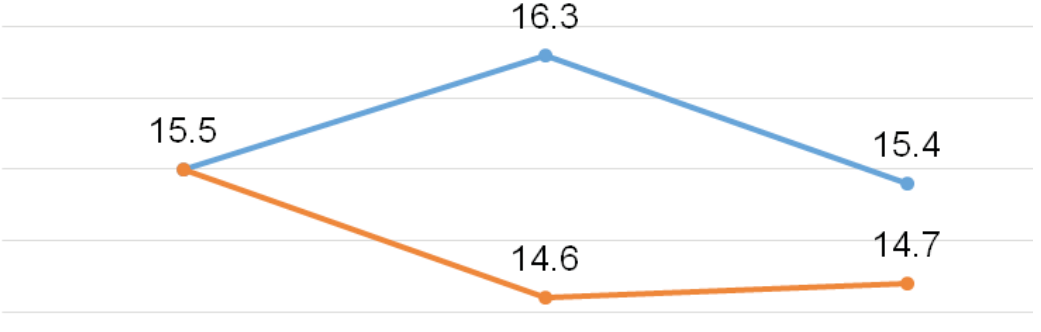

13.5

TO

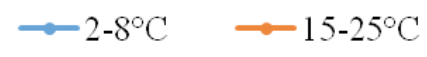

1 week

2 weeks

Time for storage

Mean $\mathrm{Cu}$ concentrations are presented for different times of storage: $\mathrm{T}_{0}-$ initial concentration.

Fig. 2. Cu stability in serum

\section{Cu stability in urine specimens}

Cu stability in $24 \mathrm{~h}$ urine control samples and $24 \mathrm{~h}$ urine of patients on D-PA administration are presented on Table 4, Figure 3 and Figure 4. The testing of stability established no significant change in urine $\mathrm{Cu}$ concentration of the control group with prolongation of storage time at room temperature $(p=0.23$ for comparison between 2 days and 3 days storage and $p=0.18$ for comparison between 3 days and 2 weeks storage). Significant difference was observed for 2 days $(p=0.03)$, almost no difference for 3 days $(p=0.046)$ and no difference for 2 weeks storage at room temperature in comparison to the initial urine $\mathrm{Cu}$. The testing at refrigeration temperature established significant difference in urine $\mathrm{Cu}$ only at the $3^{\text {rd }}$ day of storage vs. the initial urine $\mathrm{Cu}$. The prolongation of the storage time at this lower temperature was related to significant change in urine $\mathrm{Cu}\left(p=0.002\right.$ between the $2^{\text {nd }}$ and the $3^{\text {rd }}$ day; $p=0.03$ between the $3^{\text {rd }}$ day and the $2^{\text {nd }}$ week of storage).

Table 4. Stability of $24 \mathrm{~h}$ urine $\mathrm{Cu}$ in control samples and in samples with D-PA administration

\begin{tabular}{|c|c|c|c|c|c|c|c|c|}
\hline \multirow{3}{*}{$\begin{array}{l}\text { Urine } \\
\text { samples }\end{array}$} & \multirow{3}{*}{$\begin{array}{l}\text { UTO } \\
\mu \mathrm{mol} / \mathrm{L}\end{array}$} & \multirow{3}{*}{$\mathrm{ACL} \%$} & \multicolumn{6}{|c|}{ Mean differences $\%$} \\
\hline & & & & $\mathrm{UT}_{1}$ & & & $\mathrm{UT}_{3}$ & \\
\hline & & & $25^{\circ} \mathrm{C}$ & $4^{\circ} \mathrm{C}$ & $25^{\circ} \mathrm{C}$ & $4^{\circ} \mathrm{C}$ & $25^{\circ} \mathrm{C}$ & $4^{\circ} \mathrm{C}$ \\
\hline controls & 0.45 & \pm 17 & 6.6 & 8.7 & 12.7 & $27.1^{*}$ & 5.0 & 9.3 \\
\hline on D-PA & 7.66 & \pm 11.2 & -8.7 & -3.06 & -8.03 & -2.3 & -5.3 & -0.4 \\
\hline
\end{tabular}

$\mathrm{UT}_{0}$ - initial concentration; time for storage before analysis (UT $1-2$ days; $\mathrm{UT}_{2}-3$ days; $\mathrm{UT}_{3}-14$ days); $\mathrm{ACL}$ - Acceptable Change Limit 


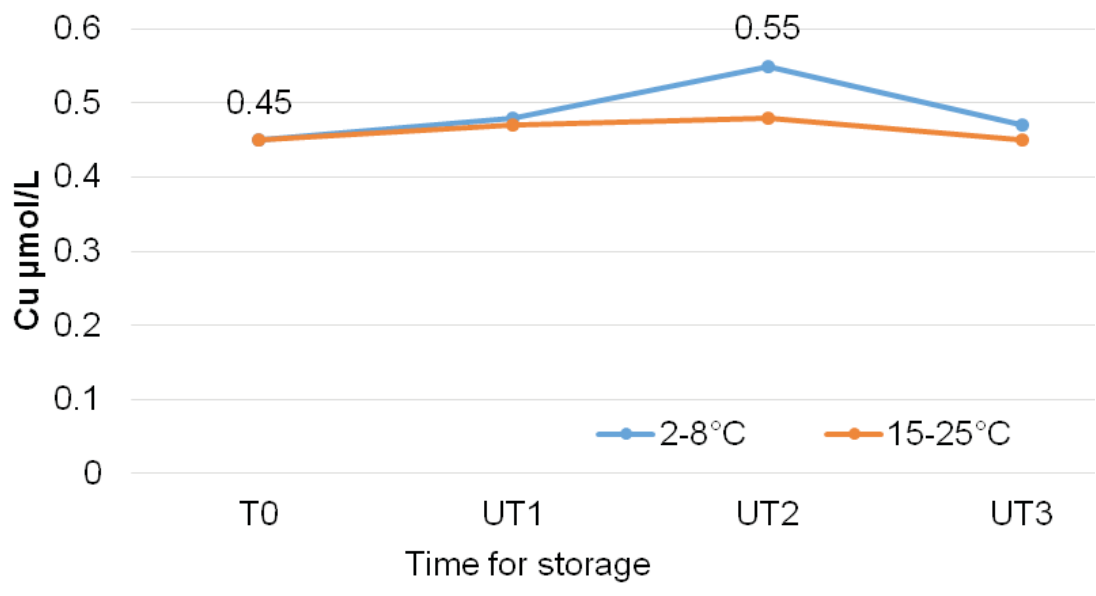

Mean $\mathrm{Cu}$ concentrations were presented for different times of storage: $\mathrm{UT}_{0}$ - initial concentration; $\mathrm{UT}_{1}-2$ days; $\mathrm{UT}_{2}-3$ days; $\mathrm{UT}_{3}-14$ days

Fig. 3. Cu stability in urine - control group

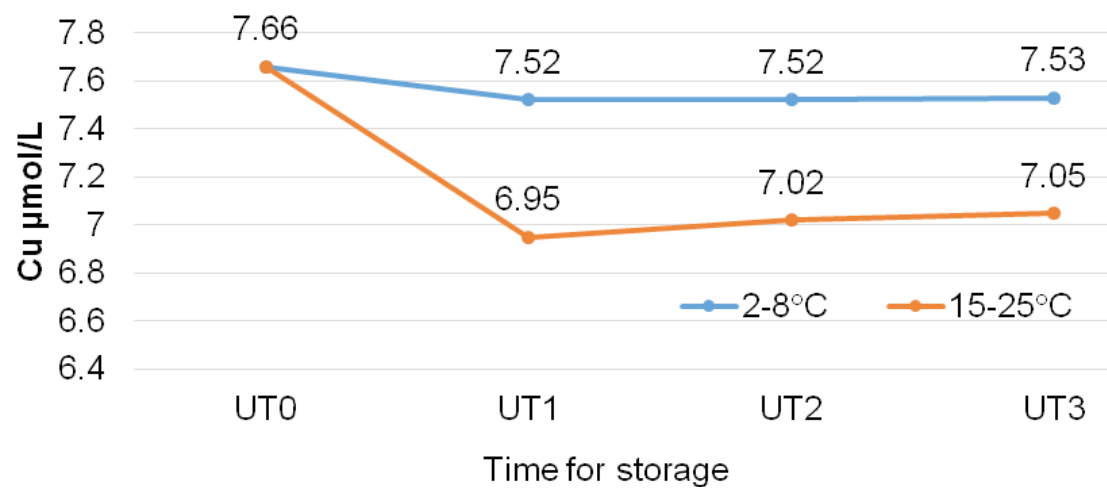

Mean $\mathrm{Cu}$ concentrations were presented for different times of storage: $\mathrm{UT}_{0}$ - initial concentration; $\mathrm{UT}_{1}-2$ days; $\mathrm{UT}_{2}-3$ days; $\mathrm{UT}_{3}-14$ days

Fig. 4. Cu stability in urine - patient on D-PA

The testing at room temperature of the stability in $24 \mathrm{~h}$ urine of patients on D-PA administration found significant change in urine $\mathrm{Cu}$ for $48 \mathrm{~h}(\mathrm{p}=0.005)$ and $72 \mathrm{~h}$ period $(p=0.008)$ and no significant difference for 2 week group $(p=0.061)$ in comparison to the initial urine $\mathrm{Cu}$. No difference was observed with prolongation of the storage time at this temperature $(p=0.429$ between $48 \mathrm{~h}$ and $72 \mathrm{~h}$ groups; $p=0.556$ between $48 \mathrm{~h}$ and 2 weeks storage groups and $p=0.845$ between 2 weeks and 72 $\mathrm{h}$ storage groups). The testing pointed no significant change for different storage time at refrigeration temperature in comparison to the initial urine concentration $(p=$ 
0.285 for $48 \mathrm{~h}$ storage, $p=0.182$ for $72 \mathrm{~h}$ storage and $p=0.627$ for 2 weeks storage) and no statistical difference in urine concentration at this temperature between different storage times ( $p=0.974$ between $48 \mathrm{~h}$ and $72 \mathrm{~h}$ groups; $p=0.949$ between 2 weeks and $48 \mathrm{~h}$ groups and $p=0.942$ between 2 weeks and $72 \mathrm{~h}$ groups).

\section{DISCUSSION AND CONCLUSIONS}

Current tendencies in laboratory medicine are orientated to detailed knowledge of each step from pre-pre-analytical phase to post-post-analytical phase in pursuit of harmony [9]. The literature data for pre-analytical steps of $\mathrm{Cu}$ analysis by FAAS are numerous but in some sense incomplete and not properly systematized [5, 6, 13]. There is a sharp need to combine criteria for trace analysis with that ones typical for clinical laboratory. In this study we tried to elucidate some important pre-analytical points of $\mathrm{Cu}$ measurements in serum and urine by FAAS from the view point of routine laboratory work.

The choice of blood collection tubes for biochemical analyses in serum depends on many factors like necessary serum volume, numbers of serum tubes for blood drawing, analytical method and etc. Comparison on the base of serum $\mathrm{Cu}$ levels found no statistical difference between both groups of tubes. Referring the reference intervals of serum Cu for Bulgarian population (males: 12.3-22.4 $\mu \mathrm{mol} / \mathrm{L}$; females: 13.2-24.3 $\mu \mathrm{mol} / \mathrm{L}$ ), the established $\mathrm{Cu}$ in water extract for both tube types was less than $1 \%$ of the expected lower limit for healthy individuals and may not be considered as significant. Our findings provided evidence that specialised BD Trace Element tubes have no advantage over BD Serum Separator tubes in regard to possible contamination risk in routine serum $\mathrm{Cu}$ measurement by FAAS. BD Serum Separator tubes are easy to use, require short processing times, yield higher serum levels, limit hazardous aerosolization, require only one centrifugation step, allow primary tube sampling, and require a single label [4]. Their use suggests possible lowering of financial costs for serum Cu tests. In the choice of vacutainers for trace analysis, the following should be considered: vacutainers absolutely clean with no risk for contamination do not exist in reality; vacutainers are not a subject of preliminary cleaning with specialized procedures; the material of tubes toppers and the type of anticoagulant, blood volume to be drawn; separation of the serum from the blood cells [4, 13].

Control of contamination is of great importance for the result quality in trace element quantitative determination. All the vessels in use for $\mathrm{Cu}$ measurement should be tested for contamination even in the cases with simple change of LOT numbers [5, 14]. Contamination can be checked by filling with de-ionized water or mild solution of nitric acid and determination of $\mathrm{Cu}$ in aqueous extracts after $48 \mathrm{~h}$ as preferred number of the tested vessels is 10 , but it could be also 5 [5]. Our testing scheme pointed $\mathrm{Cu}$ levels in water extracts of vessels for urine analyses below detection limit of the method. The filling with mild acid solution led to smaller Cu levels in the acid extracts. It seems that nitric acid might depress absorbance signal for $\mathrm{Cu}$ in flame atomic absorption analysis 
[14]. According to some criteria for contamination in trace analysis, the value of the blank has not to exceed $20 \%$ of the lowest measured value [8].

Our previous observations revealed that about half of $\mathrm{Cu}$ urine excretion is up to $6 \mathrm{~h}$ diuresis as $\mathrm{Cu}$ excretion in $6 \mathrm{~h}$ urine is $41.7 \%$ of $24 \mathrm{~h}$ cupriuria in patients with Wilson disease on D-PA therapy [7] (original idea of Prof. Z. Krastev, Clinic of Gastroenterology, University hospital St. Ivan Rilski, Medical University - Sofia, Bulgaria). In any case, reducing the time of urine collection could minimize the errors due to eventual incomplete urine collection or to eventual more pronounced $\mathrm{Cu}$ extraction from the collection vessels.

Obviously, the used plastic vessels do not contribute significantly to the final results of urine $\mathrm{Cu}$ either for control group or for the patients with $\mathrm{Cu}$ dyshomeostasis on D-PA intake. Our data suggest possible use of all pointed plastic vessels in urine Cu measurements by FAAS without preliminary cleaning with nitric acid and multiple rinsing with de-ionized water for the chosen by us conditions of pre-analytical phase. This option will simplify urine specimen handling with reducing the cost of analysis on the face of proper contamination control.

Storage of the specimens is an integral part of whole complex process of analysis for trace elements. Storage may be defined as short term ( $\leq 1$ week) and long term (up to several months). In most cases, trace element concentration is influenced by possible interaction between the specimen and the container for collection and storage or even contamination during sample preparation before the same analysis [1] thus leading to errors in the final results. Stability of one analyte in biological specimens is associated with ability to maintain the initially measured value within specified limits over period of time under specific storage conditions. Analyte concentration could be altered by contamination from airborne sources and container material or container-solution interactions (leaching, adsorption, chemical reactions), water and reagent purity, exposition by skin and clothes of patients and medical staff, too $[4,13]$. The level of the analyte could be affected also by change in the biological matrix itself because of protein denaturation, bacterial growth, $\mathrm{pH}$ change or photochemical reactions. Any of these possible factors could destroy the integrity of the specimen matrix thus leading to interference on the final result.

Storage conditions, tested in this study, were chosen with the presumption that $\mathrm{Cu}$ analysis could not be performed daily, or the sample must be shipped from remote point or the sample must be retained for repeated analysis. Exceeding ATE\% (based on analytical and biological variation) tended to reflect instability for serum $\mathrm{Cu}$. According to this criterion, our data pointed that serum $\mathrm{Cu}$ remained stable up to 2 weeks (middle term storage) at room temperature and temperature of refrigeration. Non-surprisingly, the lower temperature caused significant increase in the initial serum concentration up to 1 week because of slowing the adsorption of $\mathrm{Cu}$ ions on the wall surface of the container and reducing the bacterial growth.

Criterion for instability of urine Cu was based on only inter-assay analytical imprecision because we could not find data about biological variations for urine $\mathrm{Cu}$ in 
known databases. Exceeding of ACL was judged as significant change with instability. This study revealed more pronounced changes in $24 \mathrm{~h}$ urine samples of control individuals in comparison to $24 \mathrm{~h}$ urine samples in D-PA administration possibly due to very small $\mathrm{Cu}$ values for controls. Increase cupriuresis of healthy individuals with a peak at 3 days storage for both temperatures was observed. Even instability was concluded at refrigeration for this time. It looks as this effect could be due to inhibited adsorption of labile $\mathrm{Cu}$ pool on container wall surface and reduced bacterial growth especially underlined at lower temperature. According to these data transportation and analysis up to 2 days after urine collection should be recommended when normal urine $\mathrm{Cu}$ is expected.

Administration of D-PA led to significantly lower $\mathrm{Cu}$ at room temperature for all tested times than the initial concentration but no instability was found. This effect is less pronounced at refrigeration with no significant decrease in urine $\mathrm{Cu}$ even with prolongation of storage time. Obviously, low temperature inhibits adsorption of chelated Cu complex on wall surface of the container. Decrease in urine Cu during D-PA therapy could be also result of formation of insoluble precipitates (3).

The results suggest that use of chemical preservatives is not necessary in $\mathrm{Cu}$ urinalysis, even when samples are not tested immediately after collected portions have been delivered to the laboratory. This eliminates inconvenient step with preservation that could introduce contamination. Avoiding chemical additives also eliminated handling and storage of hazardous materials (strong acids).

IFCC Working Group "Laboratory Errors and Patient safety" has developed indicators of quality for continuous monitoring of result quality as a part of error management and control of patient safety [12]. Majority of these indicators in preanalytical phase are related to procedures for control of contamination and specimen stability. Attempts to study various aspects of pre-analytical phase (collection, transport, storage, control of contamination in all steps before the same quantitative determination) in $\mathrm{Cu}$ analysis give possibility for standardisation thus achieving high quality of the results.

\section{Acknowledgements}

This study was done by financial support of Medical University - Sofia, Grant № 45/2013; Contract № 59/2013.

\section{REFERENCES}

1. Anand, V., White, J., Hippolto, N. Some aspects of specimen collection and stability in trace element analysis of body fluids. - Clin. Chem, 1975, 21/4, 595-602.

2. Bonini, P., Plebani, M., Cerrioti, F., Rubboli, Fr. Errors in laboratory medicine. - Clin Chem, 2002, 48(5), 691-8.

3. Bornhorst, J., Hunt, J., Urry, F., McMillin, G. Comparison of Sample Preservation Methods for Clinical Trace Element Analysis by Inductively Coupled PlasmaMass Spectrometry. - Am J Clin Pathol, 2005, 123, 578-583. 
4. Bowen, R., Remaley, A. Interferences from blood collection tube components on clinical chemistry assay. - Biochem Med, 2014, 24(1), 31-44.

5. Control of Pre-analytical Variation in Trace Element Determinations, Approved Guideline, NCCLS document C38-A (ISBN 1-56238-332-9). NCCLS, 940 West Valley Road, Suite 1400, Wayne, Pennsylvania 19087 USA, 1997.

6. IUPAC, Pure and Applied Chemistry 67, 1995, 1575-1608.

7. Ivanova, I., Krastev, Z., Petkova, T., Dragneva, S. Comparison between 6-hour and 24-hour cupriuria in monitoring of therapy with D-penicillamine in patients with Wilson disease. - Biochem Med, 2013, 23(1), A1-A55.

8. Lauwerys, R., Amery, A., Bernard, A. et al. Health effects of environmental exposure to cadmium: objectives, design and organization of the Cadmibel Study: a cross-sectional morbidity study carried out in Belgium from 1985 to 1989. - Environ Health Perspect, 1990, 87, 283-9.

9. Lippi, G., Banfi, G., Church, S. et al. Preanalytical quality improvement. In pursuit of harmony, on behalf of European Federation for Clinical Chemistry and Laboratory Medicine (EFLM) Working group for Preanalytical Phase (WG-PRE). - Clin Chem Lab Med, 2014, 1-14.

10. Oddoze, C., Lombard, E., Portugal, H. Stability studies of 81 analytes in human whole blood, in serum and plasma. - Clin Biochem, 2012; 45: 464-9.

11. Plebani, M. Errors in clinical laboratory or errors in laboratory medicine? Clin Chem Lab Med. 2006; 44(6):750-59.

12. Plebani, M., Sciacovelli, L., Aita, A., Chiozza, M.L. Harmonization of pre-analytical quality indicators. - Biochem Med, 2014; 24(1):105-13.

13. Trace elements in human and animal nutrition, fifth edition. Beltsville Meryland, Walter Mertz, Academic press, 1987, Volume 1.

14. Welz, B. Atomic Absorption Spectroscopy. Verlag Chemie. Weinheim, New York, 1976.

15. Westgard QC. Desirable specifications for total error, imprecision and bias, derived from intra- and inter-individual biological variation. Available at: www.westgard.com/biodatabase1.htm\#11, 2012.

\section{Corresponding author:}

Irena Dimitrova Ivanova

Clinical Laboratory Department

University Hospital St. Ivan Rilski

Medical University

Acad. Ivan Geshov 15 Blvd, $2^{\text {nd }} \mathrm{fl}$

$\mathrm{Bg}-1431$ Sofia

e-mail address: irena.dimitrova@gmail.com 